\title{
EXAMINING ORGANIC ACID ROOT EXUDATE CONTENT AND FUNCTION FOR LEAFY VEGETABLES UNDER WATER-STRESSED CONDITIONS
}

\author{
Short communication \\ Naho KASUKAWA*, Kae MIYAZAWA \\ The University of Tokyo, Japan
}

Received: June 2020; Accepted: October 2020

\begin{abstract}
At the plants' exposal to abiotic stress, organic acids, including citric acid, are exuded through their roots. Previous studies have suggested that the exogenous application of citric acid increases antioxidant activity within the plant. Thus, we postulated that organic acids released into the surroundings during times of environmental stress may function as signaling molecules to increase antioxidant enzyme activity. To gain further insight into this phenomenon, we identified individual organic acids exuded from the roots of leafy vegetables under drought stress. We then analyzed enzyme activity and the root/shoot lengths of seedlings after treatment with the types of organic acids found to be exuded from the studied leafy vegetables, including acetic, citric, lactic, and tartaric acids. There was a significant increase in catalase and ascorbate peroxidase enzyme activity in Napa cabbage (Brassica rapa var. pekinensis) after exogenous citric acid application. Root lengths of cabbage (Brassica oleracea var. capitata) and Napa cabbage seedlings were significantly longer in citric and lactic acids pretreated seedlings compared to those of the control. The above results support the conclusion that exogenous application of citric acid alleviates drought stress. However, there is insufficient evidence to prove that organic acids act as signaling molecules to prime neighboring plants for upcoming stress.
\end{abstract}

Key words: antioxidant enzyme activity, cabbage, drought stress, Napa cabbage, organic acid, root exudate

\section{INTRODUCTION}

Seedlings of various crops are often transplanted from controlled indoor environments into harsher and less ideal outdoor environments (Liptay et al. 1998). To withstand such harsh conditions, the seedlings must be acclimated before being transplanted. Pretransplanting treatments must allow seedlings to endure the initial changes in environmental conditions while sustaining shoot and root growth until successful establishment. While there has always been a need for effective pretransplanting treatment, the more severe and frequent heat waves caused by global warming have further increased the demand (Meehl \& Tebaldi 2004; Potopová et al. 2017).
Leafy vegetables are sensitive to drought stress, which negatively affects their quality and total yield (Pavlović et al. 2018). To increase yield, an efficient transplanting system must be established.

Several pretransplanting treatments have been proposed to reduce shock, including water restriction and $\mathrm{NaCl}$ application. Both treatments lower stomatal conductance and increase cuticular wax, minimizing transpiration and improving water use efficiency (Fujiwara et al. 2002). However, these pretransplanting treatments have several limitations. When using plug trays, the effect of water restriction heavily depends on weather and is not uniform. Soil in the outermost plugs tends to dry out faster than those in the middle of the tray. 
Treatment with a $\mathrm{NaCl}$ solution was recommended as an improved method for acclimating seedlings to outside environments because it ensures uniform stress on all seedlings and potentially activates antioxidant enzyme activities (Sivritepe et al. 2008; Aktas et al. 2012). However, one of the drawbacks is that careful procedures for the disposal of $\mathrm{NaCl}$ solutions must be followed. Contact with $\mathrm{NaCl}$ solution also hinders seedling root development (Miyazawa 2016).

Citric acid (CA) treatment is reported to be as effective as water restriction and $\mathrm{NaCl}$ treatment for alleviating drought stress in cabbage (Brassica oleracea var. capitata) seedlings (Miyazawa 2011a, b). It was hypothesized that CA works through different mechanisms than those of conventional treatments, possibly acting as a signaling molecule that increases antioxidant enzyme activity in the plant to reduce oxidative damage (Miyazawa 2016). CA and other organic acids have been extensively studied as exudates secreted by plant roots when they are exposed to abiotic stresses (Sun \& Hong 2011; Song et al. 2012; Cesari et al. 2019). One possible role of these organic acids is the enhancement of positive interactions between the plant roots and soil microbes (Cesari et al. 2019), but there is still little evidence that plants avoid stress through this mechanism. We postulated that the organic acids released into the surroundings when plants are under environmental stress may be taken up by neighboring plants of the same species, triggering antioxidant activities through a signaling cascade to prime the plant for upcoming stress and harsh environmental conditions.

The present study aimed to gain further insight into this phenomenon by identifying individual organic acids in root exudate collections from cabbage, lettuce (Lactuca sativa), and Napa cabbage (Brassica rapa var. pekinensis) under drought-stress conditions. Once the organic acid components of the root exudates were categorized, we sought to determine novel functions of the said acids in alleviating drought stress through two individual experiments. In the first experiment, we analyzed the enzyme activity of growing cabbage, lettuce, and Napa cabbage seedlings. In the second experiment, we aimed to determine whether organic acids affect the tolerance of vegetable seedlings to drought. This was achieved by treating seeds with organic acids and assessing germination and subsequent seedling growth under drought stress.

\section{MATERIALS AND METHODS}

\section{Organic acid identification}

Organic acids were identified from root exudates of cabbage 'YR Seishun-nigo', Watanabe Seed, lettuce 'Quick lettuce', Asahi Farm, and Napa cabbage 'Haru-no-saiten', Watanabe Seed under simulated drought stress to determine the species-specific organic acid composition of the exudates. Eight plants per vegetable species were grown in a hydroponic kit (UH-A01E1, UIN, Osaka) for $15 \mathrm{~d}$. Environmental conditions were set at $25^{\circ} \mathrm{C}$ and $16 \mathrm{~h}$ daylight with light intensity of $200 \mu \mathrm{mol} \cdot \mathrm{m}^{-2} \cdot \mathrm{s}^{-1}$. To facilitate growth, seedlings were provided with $2 \mathrm{~cm}^{3}$ each of fertilizer: A, containing $1.6 \%$ nitrogen, $2.8 \%$ phosphoric acid, $4.2 \%$ potassium, $2.2 \%$ magnesium, $0.01 \%$ manganese, and $0.04 \%$ boron; and fertilizer B, containing $4.3 \%$ nitrogen and $6.3 \%$ potassium. After $15 \mathrm{~d}$, half of the seedlings of each treatment were randomly selected as controls and the other half was subjected to drought stress by placing them in vials with $25 \mathrm{~cm}^{3}$ of $15 \%$ polyethylene glycol 8000 (PEG) solution. The PEG-treated plants were kept in solution in the hydroponic kit alongside control plants for a maximum of two days, or until apparent signs of wilting were observed. After the treatment, both PEG and control plants were placed into new vials containing $25 \mathrm{~cm}^{3}$ of $0.5 \%$ $\mathrm{CaCl}_{2}$ and kept in the hydroponic kit for one day. After $24 \mathrm{~h}$, a solution sample from each plant was analyzed using HPLC (Prominence LC20, Shimadzu, Kyoto). A Supelcogel $\mathrm{H}$ column $(30 \mathrm{~cm} \times$ $7.8 \mathrm{~mm}$ ) was used with $0.1 \%$ phosphoric acid as a mobile phase, at a flow rate of $0.5 \mathrm{~cm}^{3} \cdot \mathrm{min}^{-1}$, and injection volume of $20 \mu \mathrm{l}$ were used. Three percent of CA, tartaric (TA), malic (MA), succinic (SA), lactic (LA), and acetic acid (AA) were used as standard solutions. Results are shown in Figure 1 with error bars representing standard deviations.

\section{Catalase and ascorbate peroxidase analysis}

To analyze changes in the enzyme activities of catalase (CAT) and ascorbate peroxidase (APX) after organic acid pretreatment, seedlings were grown in a 128 cell plug-tray filled with culture soil (Tanemaki-baido, Takii \& Co., Kyoto). 
Seedlings were kept at $20^{\circ} \mathrm{C}$ and a $16 \mathrm{~h}$ daylight schedule, using a fluorescent lamp (sunshine daylight lamp $36 \mathrm{~W}$ rapid, Hitachi, Japan), for 27 days. Four seedlings were randomly selected for each of the five organic acid pretreatments determined by the previous organic acid identification experiment. Seedling roots were submerged in $5 \mathrm{mM}$ treatment solutions of either CA, TA, LA, AA, or distilled water (control) for $20 \mathrm{~s}$ and then left at room temperature for an hour before enzyme activity quantification. For this, aboveground portions of the seedlings were ground using a mortar and liquid nitrogen, and homogenized for $10 \mathrm{~s}$ in a $10 \mathrm{~cm}^{3} \mathrm{ex}-$ traction buffer solution containing $50 \mathrm{mM} \mathrm{Na-P}$ buffer ( $\mathrm{pH} 7.0$ ), $2 \%$ polyvinylpyrrolidone, and $0.1 \mathrm{mM}$ EDTA, using a homogenizer (NS-52, Microtec, Japan). For CAT, two $1 \mathrm{~cm}^{3}$ solutions were taken from each sample and centrifuged at 15,000 rpm for $15 \mathrm{~m}$. Enzyme activity was determined using a spectrophotometer (UV mini-1240, Shimadzu Corporation, Kyoto) to monitor the decrease in absorbance, following the method by Nakano and Asada (1981). For APX, $160 \mu 1$ of $100 \mathrm{mM}$ ascorbate was added to the homogenate solution, and then two $1 \mathrm{~cm}^{3}$ solutions were centrifuged in the same way as the CAT samples. Absorbance was recorded for $180 \mathrm{~s}$ at $290 \mathrm{~nm}$, immediately after pipetting $200 \mu \mathrm{l}$ of sample-solution supernatant, $1200 \mu \mathrm{l}$ of $50 \mathrm{mM} \mathrm{K-PO} 4$ buffer, $200 \mu 1$ of $1 \mathrm{mM}$ EDTA, $200 \mu 1$ of $5 \mathrm{mM}$ ascorbate, and $200 \mu 1$ of $1 \mathrm{mM} \mathrm{H}_{2} \mathrm{O}_{2}$ into the cuvette. The effects of the treatments on the enzyme activities of each vegetable were tested using a two-sided Dunnett test (R v. 3.6.1). Results are shown in Figures 2-4 with error bars representing standard deviation.

\section{Germination and post-germination growth analysis}

We conducted the germination and post-germination growth experiment after organic acid identification and CAT and APX analysis. As we concluded from our earlier experiments that organic acids had no effect on lettuce, we performed analyses on only cabbage and Napa cabbage. Cabbage and Napa cabbage seeds were surface-sterilized with a $1 \%$ sodium hypochlorite solution for $5 \mathrm{~min}$. After sterilizing, seeds were divided into three pretreatment groups of control (distilled water), $5 \mathrm{mM} \mathrm{CA}$, or $5 \mathrm{mM} \mathrm{LA}$, and soaked for $1 \mathrm{~h}$ in the respective solutions. Seeds of each group were further divided into two treatments; regular watering during germination (RW) and application of PEG solution to impose drought stress during germination (PEG). Each treatment was replicated three times. Ten treated seeds were placed onto a petri dish with one layer of Whatman No. 2 filter paper, and $5 \mathrm{~cm}^{3}$ of either distilled water or $15 \%$ PEG 8000 solution was added to each petri dish with a pipette. Solutions were changed every three days if the experiment was extended past 72 h. At 72 h (for Napa) and $96 \mathrm{~h}$ (for cabbage), final germination percentage, root, and shoot length were recorded.

Statistical significance was tested using a twoway analysis of variance (ANOVA), followed by a Tukey HSD test when necessary, for each plant species. All calculations were done in $\mathrm{R}$ v. 3.6.1 (R Core Team 2019).

\section{RESULTS}

\section{Organic acid identification}

Neither MA nor SA were identified in cabbage, lettuce, or Napa cabbage, regardless of treatment. However, other organic acids were identified and varied between vegetable species. In cabbage, no organic acids were identified in control samples, while PEG-treated samples had noticeable concentrations of CA, TA, LA, and AA in their root exudates (Fig. 1A). In lettuce, CA, TA, and LA were detected in control samples, while CA was the only exudate identified in PEG-treated samples (Fig. 1B). With Napa cabbage, CA, TA, and LA were detected in control samples, while CA, LA, and AA were detected in PEG-treated samples (Fig. 1C).

Catalase and ascorbate peroxidase enzyme analysis CAT and APX enzyme activity of cabbage and lettuce were relatively similar among different organic acid pretreatments and did not show any significant difference from the control (Fig. 2, 3). 

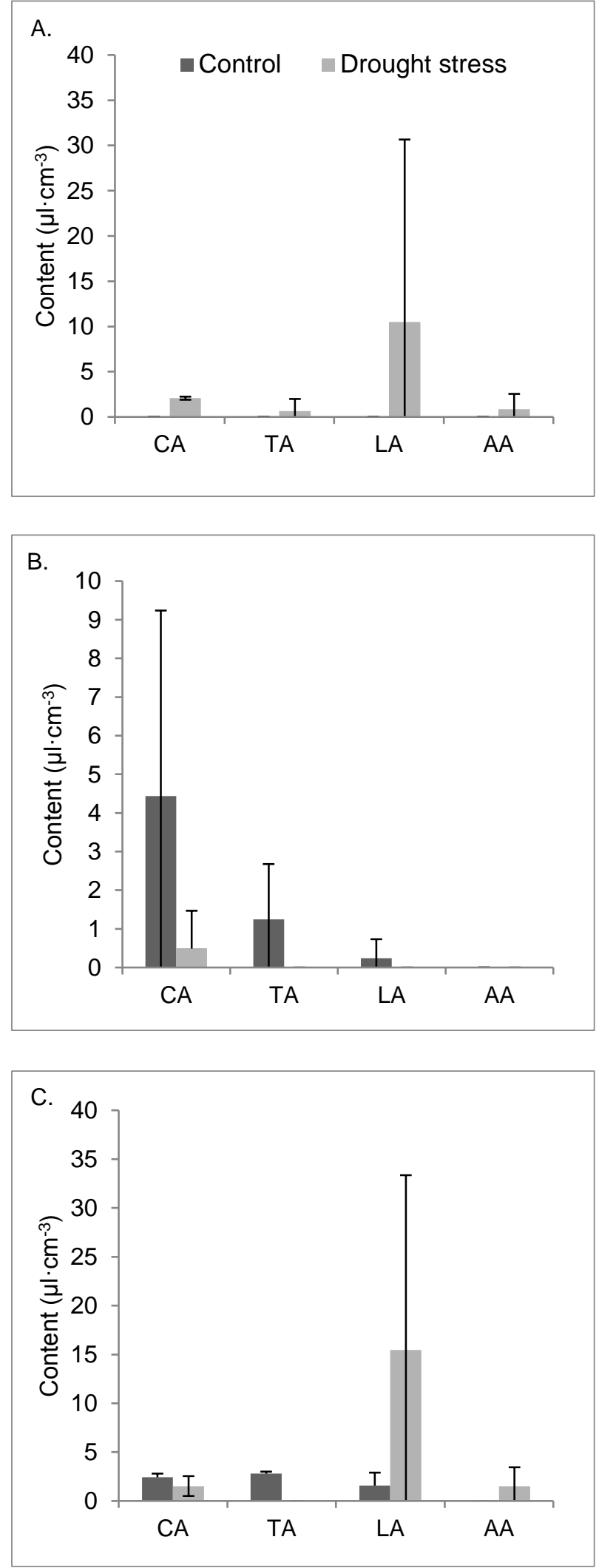

Figure 1. Organic acid secretions $\left(\mu 1\right.$ per $\left.\mathrm{cm}^{3}\right)$ of $(\mathrm{A}) \mathrm{cab}$ bage, (B) lettuce, and (C) Napa cabbage compared between control and drought stress (15\% PEG) treatments. Error bars represent the standard deviation; $(n=4)$
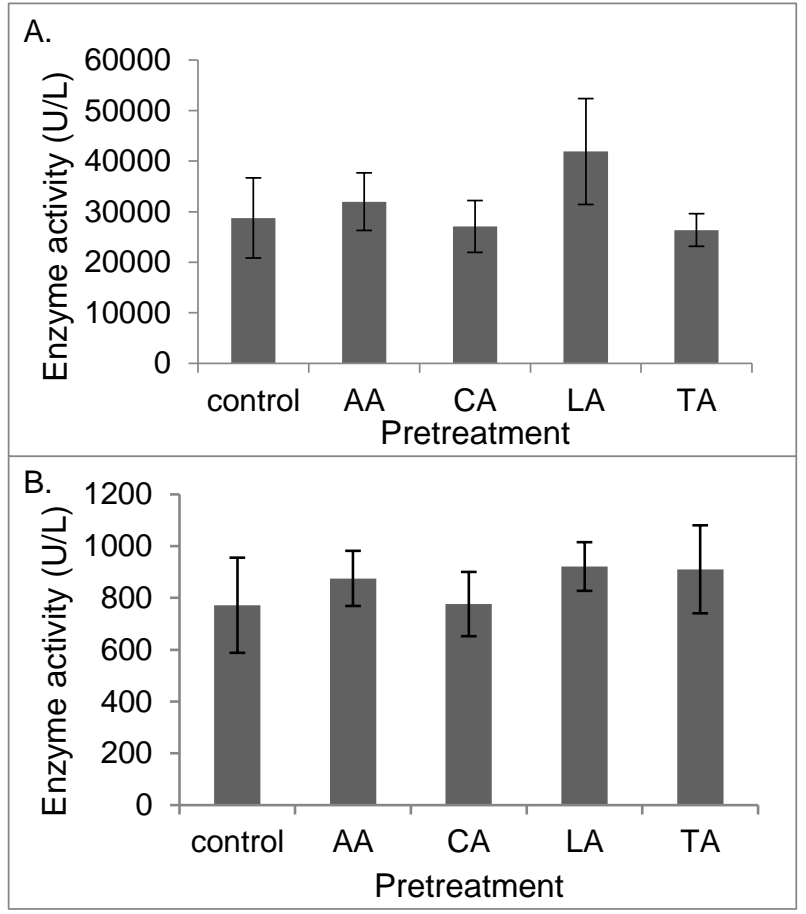

Figure 2. Enzyme activity (U/L) recorded for cabbage seedlings subjected to control, and $5 \mathrm{mM}$ of respective organic acid treatments: (A) catalase (CAT), (B) ascorbate peroxidase (APX). Error bars represent the standard deviation; $(n=4)$
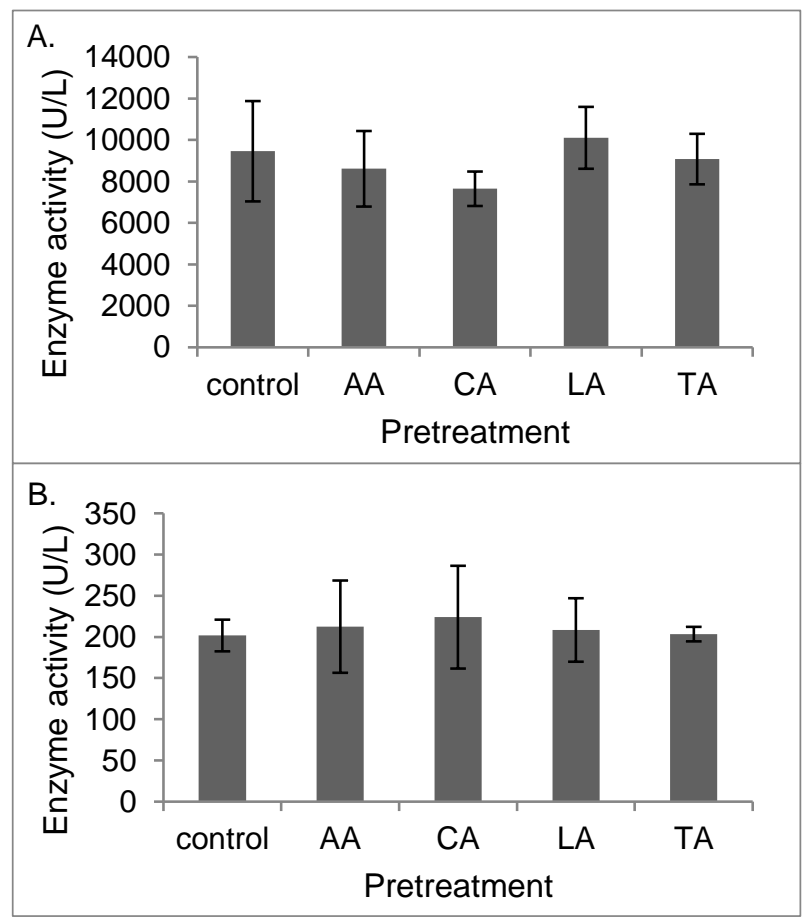

Figure 3. Enzyme activity (U/L) recorded for lettuce seedlings subjected to control, and $5 \mathrm{mM}$ of respective organic acid treatments: (A) catalase (CAT), (B) ascorbate peroxidase (APX). Error bars represent the standard deviation; $(n=4)$ 
In Napa cabbage, CAT enzyme activity was higher after the CA treatment compared to that of the control (Fig. 4A, p = 0.004). Similarly, APX enzyme activity was higher in the CA treatment than in the control (Fig. 4B, $\mathrm{p}=0.002$ ).

Germination and post-germination growth analysis There were no significant differences in germination rate among CA and LA pretreatments (control/water) and drought-stress treatments (RW, PEG) for either cabbage or Napa cabbage seeds. Average germination rate of all pretreatment and drought-stress treatment groups were 99\% and 93\% for cabbage and Napa cabbage, respectively.

For cabbage, seed pretreatment with CA and LA had a significant effect on root length (Table 1). CA and LA pretreated seedlings had significantly longer roots than those of control non pretreated seedlings ( $p<0.001$, Fig. 5A). We found an interaction effect between seed pretreatment and drought-stress treatment in cabbage shoots. Shoots of control seedlings in the RW group were significantly longer than those of the control with PEG group ( $p<0.001$, Fig. 5B). There was no significance in shoot length of seedlings pretreated with CA and LA when grown under RW or PEG regime.

In Napa cabbage, both pretreatment and drought stress treatment had a significant effect on root length (Table 1). Root length under the CA and LA pretreatments was longer than that of the control plants ( $\mathrm{p}<0.001$, Fig. 6A). In addition, the roots of PEG-treated seedlings were significantly longer than those of the RW seedlings. For shoot length, only the effect of drought-stress treatment was significant. Shoots of RW seedlings were significantly longer than those of the PEG-treated plants (Fig. 6B).

Table 1. P-values of two-way ANOVA for determining significance in root length and shoot length for cabbage and Napa cabbage under different organic acid pretreatments and drought stress treatments

\begin{tabular}{lcccc}
\hline & \multicolumn{2}{c}{ Cabbage } & \multicolumn{2}{c}{ Napa cabbage } \\
\hline & Root & Shoot & Root & Shoot \\
\hline $\begin{array}{l}\text { Pretreatment } \\
(\mathrm{P})\end{array}$ & $<\mathbf{0 . 0 0 1}$ & 0.122 & $<\mathbf{0 . 0 0 1}$ & 0.191 \\
\hline $\begin{array}{l}\text { Drought stress } \\
(\mathrm{D})\end{array}$ & 0.332 & $<\mathbf{0 . 0 0 1}$ & $<\mathbf{0 . 0 0 1}$ & $\mathbf{0 . 0 0 9}$ \\
\hline $\mathbf{P} \times \mathrm{D}$ & 0.055 & $\mathbf{0 . 0 0 2}$ & 0.126 & 0.101 \\
\hline
\end{tabular}

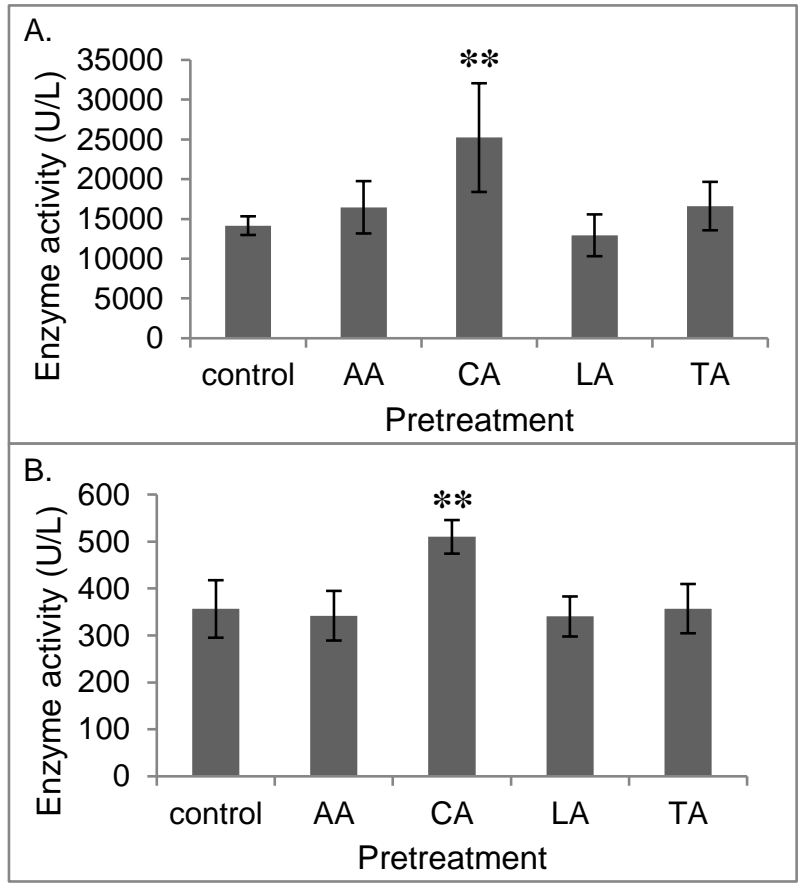

Figure 4. Enzyme activity (U/L) recorded for Napa cabbage seedlings subjected to control, and $5 \mathrm{mM}$ of respective organic acid treatments: (A) catalase (CAT), (B) ascorbate peroxidase (APX). Error bars represent the standard deviation; $(n=4)$; a double asterisk indicates a significant difference when compared to the control $(\mathrm{p}<0.01)$
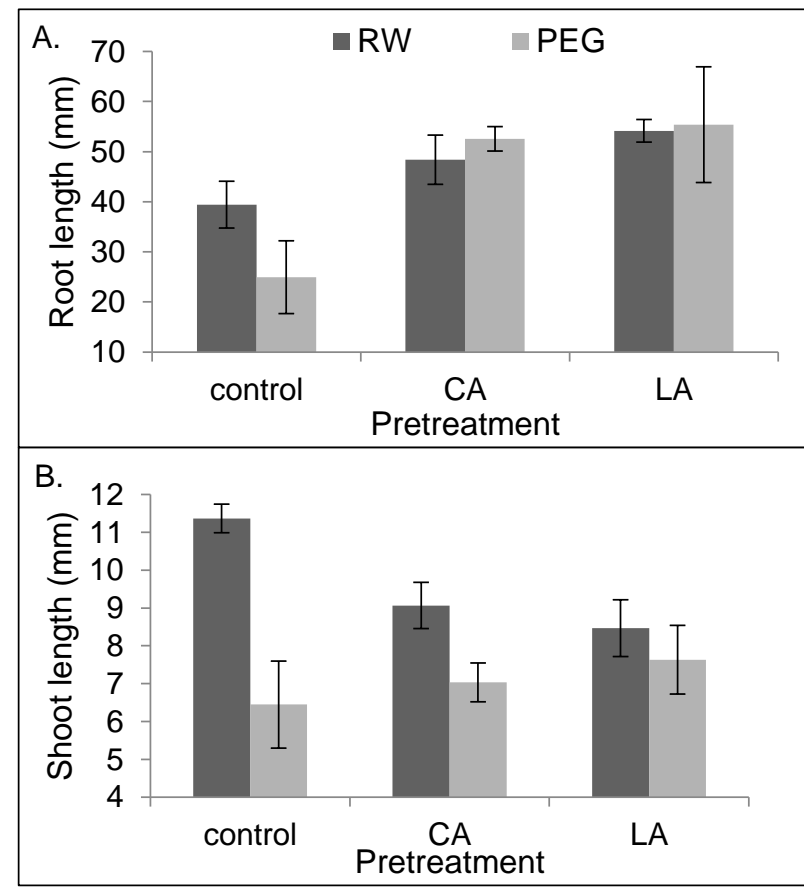

Figure 5. (A) root length and (B) shoot length under regular watering during germination (RW)/application of PEG solution (PEG) treatment and varying organic acid pretreatments for cabbage. Error bars represent the standard deviation; $(\mathrm{n}=30)$ 

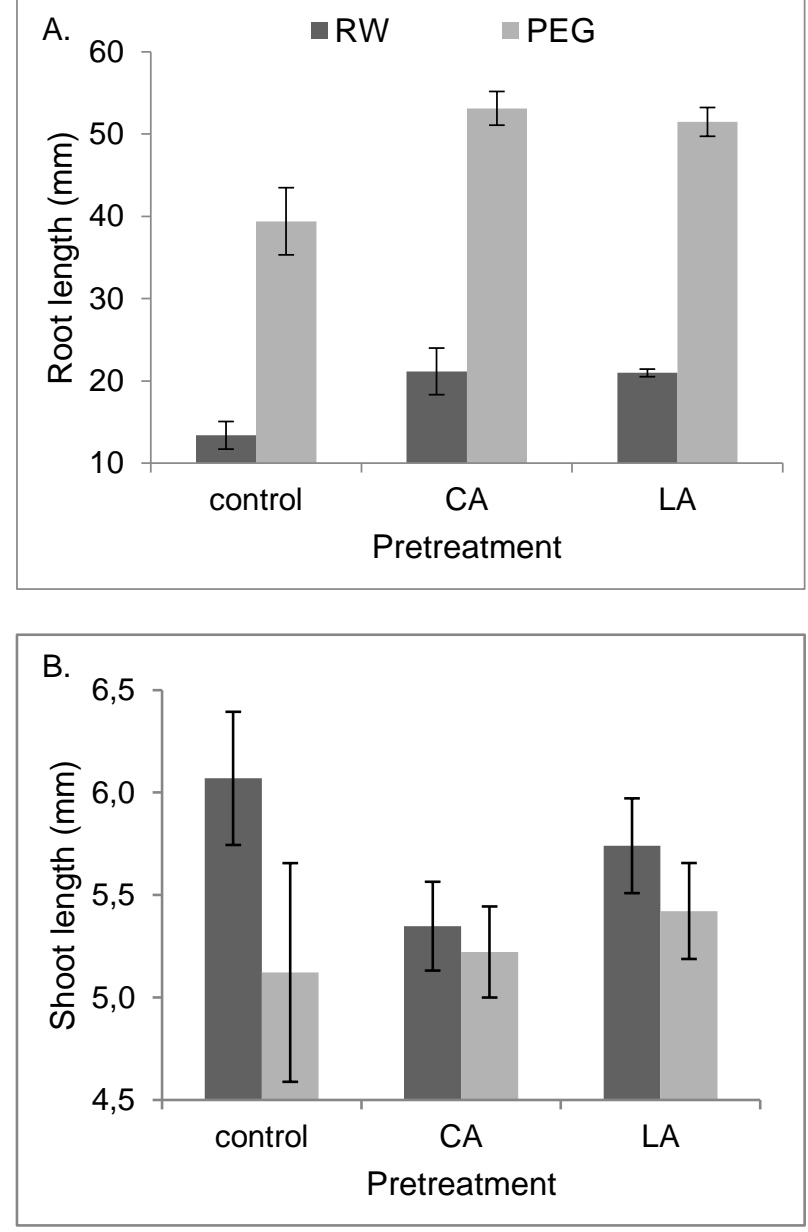

Figure 6. (A) root length and (B) shoot length under regular watering during germination (RW)/application of PEG solution (PEG) treatment and varying organic acid pretreatments for Napa cabbage. Error bars represent the standard deviation; $(\mathrm{n}=30)$

\section{DISCUSSION}

We found that cabbage roots exude LA, CA, TA, and AA, while Napa cabbage roots uniquely exude LA and AA when treated with PEG to impose drought stress. To determine whether the above organic acids functioned as signaling molecules that trigger antioxidant activities to prime plants against environmental stress, we measured CAT and APX activity after exogenous application of the respective organic acid solutions. Significant increases in enzyme activity were only observed in Napa cabbage treated with CA solution. As CA was not one of the exuded organic acids unique to imposed drought stress, we concluded that there was insufficient evidence to confirm our hypothesis that organic acids can function as plant-plant signaling molecules that trigger antioxidant activities in preparation for environmental stress. It has been shown that foliar application of CA prior to stress can reduce stress damage and increase antioxidant activity (ElTohamy et al. 2013; Hu et al. 2016). Therefore, rather than acting as a signal through the roots, it is likely that the antioxidant activity was activated directly by the increased CA concentration in the plant.

On the other hand, germination experiments of cabbage and Napa cabbage resulted in increased root lengths in CA and LA pretreated seedlings, regardless of watering method. This is in line with our findings that CAT and APX activity increased in Napa cabbage after exogenous application of CA solution, even without imposed drought stress. Although the potential connection between increased root growth and antioxidant enzyme activity was not explored in the present study, Yan (2015) observed correlated activities between germination percentage and CAT/peroxidase activity in Chinese cabbage seeds that underwent priming treatment. While control pretreated cabbage seedlings under RW had significantly longer shoots than those under PEG, there were no significant differences between shoot lengths of seedlings under RW and PEG when pretreated with CA and LA solutions. This suggests that CA and LA may play a role in sustaining shoot growth in cabbage, even under drought conditions imposed by PEG.

Our results support conclusions from previous papers that the exogenous application of CA can alleviate drought stress in leafy vegetables. CA pretreatment resulted in increased CAT and APX activity in Napa cabbage and increased root length in post-germination seedlings for both cabbage and Napa cabbage. However, CA was not uniquely exuded from Napa cabbage roots when exposed to drought stress. Thus, we conclude that there is insufficient evidence to support our hypothesis that plants release such organic acids in times of environmental stress as signaling molecules to be taken up by neighboring plants to trigger antioxidant activities. 


\section{Acknowledgments}

We thank the University of Tokyo Institute for Sustainable Agro-ecosystem Services for the technical assistance and for permission to use the research lab for conducting this experiment. This work was financially supported by the Start-up Research Fund from the University of Tokyo.

\section{REFERENCES}

Aktas H., Abak K., Eker S. 2012. Anti-oxidative responses of salt-tolerant and salt-sensitive pepper (Capsicum anпиит L.) genotypes grown under salt stress. Journal of Horticultural Science and Biotechnology 87: 360-366. DOI: 10.1080/14620316.2012.11512877.

Cesari A., Paulucci N., López-Gómez M., HidalgoCastellanos J., Lluch Plá C., Dardanelli M.S. 2019. Restrictive water condition modifies the root exudates composition during peanut-PGPR interaction and conditions early events, reversing the negative effects on plant growth. Plant Physiology and Biochemistry 142: 519-527. DOI: 10.1016/j.plaphy.2019.08.015.

El-Tohamy W.A., El-Abagy H.M., Badr M.A., Gruda N. 2013. Drought tolerance and water status of bean plants (Phaseolus vulgaris L.) as affected by citric acid application. Journal of Applied Botany and Food Quality 86: 212-216. DOI: 10.5073/jabfq.2013.086.029.

Fujiwara T., Yoshioka H., Kumakura H., Sato F., Inoue S. 2002. Effects of $\mathrm{NaCl}$ application conditions on the quality of cabbage plug seedlings. Horticultural Research 1: 169-173. DOI: 10.2503/hrj.1.169. [in Japanese with English abstract]

Hu L.X., Zhang Z.F., Xiang Z.X., Yang Z.J. 2016. Exogenous application of citric acid ameliorates the adverse effect of heat stress in tall fescue (Lolium arundinaceum). Frontiers in Plant Science 7; 179; 11 p. DOI: 10.3389/fpls.2016.00179.
Liptay A., Sikkema P., Fonteno W. 1998. Transplant growth control through water deficit stress - A review. HortTechnology 8: 540-543. DOI: 10.21273/horttech.8.4.540.

Meehl G.A., Tebaldi C. 2004. More intense, more frequent, and longer lasting heat waves in the $21 \mathrm{st}$ century. Science 305: 994-997. DOI: 10.1126/science. 1098704.

Miyazawa K. 2011a. Low organic matter application increases drought tolerance of cabbage seedlings. I. Effects of sugars and citric acid. Japanese Journal of Soil Science and Plant Nutrition 82: 298-301. DOI: 10.20710/dojo.82.4_298. [in Japanese]

Miyazawa K. 2011b. Low organic matter application increases drought tolerance of cabbage seedlings. II. Effect of citric acid application. Japanese Journal of Soil Science and Plant Nutrition 82: 302-304. DOI: 10.20710/dojo.82.4_302. [in Japanese]

Miyazawa K. 2016. Drought stress alleviation of cabbage seedlings by citric acid application. Acta Horticulturae 1112: 101-108. DOI: 10.17660/actahortic.2016.1112.14.

Nakano Y., Asada K. 1981. Hydrogen peroxide is scavenged by ascorbate-specific peroxidase in spinach chloroplasts. Plant and Cell Physiology 22: 867880. DOI: 10.1093/oxfordjournals.pcp.a076232.

Pavlović I., Petřík I., Tarkowská D., Lepeduš H., Bok V.V., Brkanac S.R. et al. 2018. Correlations between phytohormones and drought tolerance in selected Brassica crops: Chinese cabbage, white cabbage and kale. International Journal of Molecular Sciences $19 ; \quad 2866 ; 23$ p. $\quad$ DOI: 10.3390/ijms19102866.

Potopová V., Zahradníček P., Štěpánek P., Türkott L., Farda A., Soukup J. 2017. The impacts of key adverse weather events on the field-grown vegetable yield variability in the Czech Republic from 1961 to 2014. International Journal of Climatology 37 : 1648-1664. DOI: 10.1002/joc.4807. 
R Core Team 2019. The R Project for statistical computing. The R Foundation for Statistical Computing, Vienna, Austria. www.r-project.org

Sivritepe N., Sivritepe H.Ö., Türkan I., Bor M., Özdemir F. 2008. NaCl pre-treatments mediate salt adaptation in melon plants through antioxidative system. Seed Science and Technology 36: 360-370. DOI: 10.15258/sst.2008.36.2.09.

Song F., Han X., Zhu X., Herbert S.J. 2012. Response to water stress of soil enzymes and root exudates from drought and non-drought tolerant corn hybrids at different growth stages. Canadian Journal of Soil Science 92: 501-507. DOI: 10.4141/cjss2010-057.

Sun Y.-L., Hong S.-K. 2011. Effects of citric acid as an important component of the responses to saline and alkaline stress in the halophyte Leymus chinensis (Trin.). Plant Growth Regulation 64: 129-139. DOI: $10.1007 / \mathrm{s} 10725-010-9547-9$.

Yan M. 2015. Hydropriming promotes germination of aged napa cabbage seeds. Seed Science and Technology 43: 303-307. DOI: 10.15258/sst.2015.43.2.12. 